\title{
Analysis of Changes in Maternal and Child Health Policy in a Capital of Northeastern Brazil: Dilemmas and Challenges for Care
}

Ricardo de Sousa Soares ${ }^{1}$, Ulisses Umbelino dos Anjos ${ }^{2}$, Rodrigo Pinheiro Toledo Vianna ${ }^{3}$, Adernanda De Rocco Guimarães ${ }^{4}$, Luciano Bezerra Gomes ${ }^{5}$, Juliana Sousa Soares de Araújo ${ }^{6}$, Lucas Henrique Paupitz Mendes 7

\section{Abstract}

Background: The care to women's health in pregnancy, childbirth and puerperium has being changing with the development of Brazil's health policies. To discuss the implementation of the changes in perinatal care policy in a capital of the Northeast, analyzing the changes in the care and in organization of health services.

Methods: We used a qualitative approach with data collection between May and December 2015, with weekly visits in a Maternity, document review of municipal government, semi-structured interviews with users of the service, municipal managers, local managers of the federal government, professionals and managers of a municipal maternity. We conducted a focus group with volunteer doula.

Findings: Prenatal stands out difficulties in accessing some routine tests in primary care. It is still in the design phase to build a normal delivery centers in the city. Realize humanization of care initiatives as the introduction risk classification and the volunteer doulas program in a maternity, despite being hegemonic traditional obstetric model. There is no state regulation obstetric reflecting in the demand for care of parturient in obstetric emergency.

Conclusions: We perceive an incipient implementation of some key aspects of the perinatal care policy in the city, however, also identified several experiments in the routine of services pointing to the qualification of humanized care during labor and childbirth.
1 PhD Student in Health Decision Models, Federal University of Paraíba. Professor at Department of Health Promotion, Federal University of Paraíba. João Pessoa, Paraíba. Brazil.

$2 \mathrm{PhD}$ in Statistics. Department of Statistics, Federal University of Paraíba. João Pessoa Brazil.

$3 \mathrm{PhD}$ in Public Heath. Department of Nutrition, Federal University of Paraíba. João Pessoa Brazil.

4 Sanitarian. João Pessoa. Paraíba. Brazil.

$5 \mathrm{PhD}$ in Clinical Medicine. Department of Health Promotion, Federal University of Paraíba. João Pessoa, Paraíba. Brazil.

6 Master in Health Decision Models. Department of Health Promotion, Federal University of Paraíba. João Pessoa, Paraíba. Brazil.

7 Medical student. Federal University of Paraíba. João Pessoa, Paraíba. Brazil.

\section{Contact information:}

\section{Ricardo de Sousa Soares.}

Address: Federal University of Paraíba, Cidade Universitária, Castelo Branco, João Pessoa, Paraíba. Brazil.

Tel: +558332167242 .

झ ricardosousasoares@gmail.com

Keywords

Health Evaluation; Delivery of Health Care, Integrated; Maternal and Child Health; Perinatal Care; Humanization of Assistance. 


\section{Introduction}

The care to women's health in pregnancy, childbirth and puerperium, as well as the child's in the first months of life, has always stood out on the development of Brazil's health policies. In 2011, the Brazilian government launched the Stork Network, a program to qualify the integrated health services for prenatal, childbirth and care to children up to two years old. This program was created through an ordinance and other later regulations with the objectives to: build changes on the care model, focusing on comprehensive health care for women and children up to two years old; organize the care network guaranteeing access, reception and resolubility; and reduce maternal and child mortality with emphasis on its neonatal and maternal component. [1]

While building a logical model for the Stork Network, a study identified, in the government documents related to the program, four major problems: the high number of unwanted pregnancies, difficulty of access to a quality prenatal, pregnant women going from hospital to hospital looking for available rooms, inadequate and non-evidence-based practices in labor and birth. [2]

The appearance of the Stork Network received important criticism from women related social movements. The term "stork" was associated to the very notion of transportation, an idea of womanhost, which goes against a comprehensive women's health policy and puts aside debates such as decriminalization of abortion, with regard to women's right to their own body, which is a primary discussion for the feminist movement. Otherwise, it was recognized the need for right of access to a quality prenatal and labor, as well as the demand for overcoming the hegemonic obstetric model, seeking a childbirth model that takes each woman's singularities into consideration. [3]

The program was organized in four components: prenatal; labor and birth; puerperium and comprehensive care to children; and logistical system: sani- tary transport and regulation. We emphasize access as a central issue in the ordinance that implements the Stork Network, as well to low-risk prenatal and necessary tests and to high-risk prenatal and obstetric emergencies. Furthermore, formalizes the importance to introduce to the pregnant woman her reference maternity to delivery. Regarding the van labor and birth, it is normalized the idea of vacancy for every parturient that seeks a maternity (always vacant), and good practices of labor and birth are reinforced according to the World Health Organization (WHO), such as the guarantee of a companion in labor, birth and puerperium. Also stand out in the ordinance the stimulus to creation of collegiate managers, financing of normal birth centers and houses for pregnant women, babies and mothers, as well as the incentive to articulate the services network of counties, overcoming fragmentation and promoting pacts between the federated entities. [1]

Some proposals for the Stork Network, such as changing the hegemonic obstetric model and promoting good obstetric practices, ratifies initiatives launched on the last two decades. The World Health Organization in 1996, published a series of recommendations based on a rating supported by clinical evidence divided in four levels: A) useful practices that must be encouraged; B) harmful or ineffective practices that must be abolished; $C$ ) non-evidence-based, which must be used with caution; D) frequently inappropriate. Among the practices that must be encouraged, it could already be found proposals such as the right to a companion of choice, freedom of position and nonsupine position, early contact between mother and baby, privacy and information access for the mother. Among the interventions that must be discouraged, there were episiotomy, supine position, routine intravenous infusion during labor and birth. [4]. The right to a companion, access to childbirth assistance, information about the reference maternity and humanized care had already been 
included in the Prenatal and Birth Humanization Program (PHPN) published 10 years before, were ratified in the Stork Network. However, in this new programa, was proposed expand the focus of the care beyond the biomedical model, investing in building birthing centers, and also brings recognition to traditional midwives' work, including the provision of kits containing equipment and basic inputs for childbirth assistance. [1, 5] Many of the issues advocated for the promotion of good labor and birth practices have already been incorporated in normalizations and other laws related to the Unified Health System (SUS), but even so, childbirth is hegemonically seen as a biomedical issue and the changes in the care model still face the changes of practices in everyday work. [6] This obstetrical model dispute is not an issue restricted to Brazil, but is present in many countries with their different forms of organization.

The National Institute for Health and Care Excellence (NICE), from the British health system, has recently presented a revision on current evidences about childbirth care, which culminated in, among other matters, the recommendation that low-risk pregnancy women have their childbirth assistance in midwife-led unit or at home, so that they are under lesser risk of unnecessary procedures and interventions. [7] This recommendation has reignited the debate about the best location for labor and birth and about how to restructure the health service networks that currently perform the care for most pregnant women in obstetric centers, as discussed in the comparison between service networks of countries such as the United States and England, the last one already with clear regulations that point to an obstetrical model change. [8] In a study in Canada, with the objective to decrease the rate of caesarean sections, some hospitals, which had caesarean indications audited and incentive to good obstetrical practices, were followed and showed a discreet, but significant reduction of caesarian sections, especially on high-risk pregnancies. [9]
In this complex context, in which national policies point to certain care models, though with no established consensus, yet another aspect stands out: out of the eight objectives proposed by the United Nations for the millennium, to be reached between 2000 and 2015, Brazil will reach all but maternal mortality reduction. Although it has decreased, we are still well over the recommended, in great part because of very high rates of caesarians and the illegal practice of abortion. From this perspective, we consider that analyzing the implementation experiences of the Stork Network, in different locations, is a relevant measure in the academic debate that proposes to contribute to overcoming these challenges. In this sense, the present article analyzes the implementation of this program in a capital of the Brazilian Northeast.

The city of João Pessoa, capital of Paraíba, concentrates various resources of perinatal care in the state. It is the main reference in the health region for high-risk prenatal and childbirth, besides being the only reference of the state for some medical subspecialties. The care to low-risk prenatal is done by the 187 Family Health teams, which cover 83\% of the population, and by the basic health units that serve the uncovered areas of the city. [10] The highrisk prenatal occurs in the specialties services, some of which are linked to the hospital network. The normal risk or high-risk childbirths happen in four institutions: Cândida Vargas Institute (ICV), which is the biggest maternity of the state, managed by the county of João Pessoa; Frei Damião Maternity and Edson Ramalho Hospital, managed by the state; and Lauro Wanderley University Hospital (HULW), of the Federal University of Paraíba (UFPB), linked to the federal government.

The Cândida Vargas Institute performs about 650 births every month and, among the other four, is the main establishment for childbirth care. It has a structure for maternal and neonatal intensive care unit, besides being part of the whole policy of national qualification of maternal and child assistance, 
such as: Kangaroo Method, which qualifies the premature neonate assistance, the Child Friendly Hospital Initiative (IHAC), which stimulates breastfeeding and is a state reference.

In this article we discuss the implementation of the Stork Network Program in João Pessoa, analyzing the transformations related to the organization of the service network. Although the starting point is the components of the Program, these are just initial guides to present the path of the changes identified in the perinatal network in João Pessoa.

\section{Methods}

This is a qualitative study, based on the perspective of the in-mundo researcher, the idea that the subject and object of study cannot be separated, that it is necessary to be dirty or contaminated with local reality, and that the study must be built from the demands of multiple subjects/actors in this field [11]. This research analyzes the way in which are produced relations that expand the possibility of developing meetings for care among workers and patients of health services, in which the formal health networks are a relevant but not sufficient aspect.

The analysis on the production of care demanded, among other aspects, comprehension of the formal implantation of the policies of attention normalized by the government, which is the focus of this article. Therefore, we analyzed the implantation of the program in the city of João Pessoa, studying its internal dynamic and comprehending its articulation in the restructuring of the state network. To this end, the field work demanded weekly researching activities in the largest maternity of the city, between May and December of 2015, and occasional moments in other maternities. We did semistructured interviews with municipal managers, the Ministry of Health supporter, professionals and managers of a reference maternity of the city, besides non-structured interviews with patient of the city services. In total, there were 19 interviews, being 2 from doulas, 3 from the nursing team professionals, 4 from management technicians and 8 from patients of the network. We also made a focal group with participants from the doula's group in the city. The record of the interviews and the focal group was done through audio recording. We recorded our experiences in a field diary, creating reflections for analysis.

The interviews and the focal group happened between May and July of 2015. The collected data were systemized following the chronologic criteria of the reported actions, in order to clarify the connections and effects of the activities developed over time, besides being categorized according to the components of the Stork Network Policy to make it easier to compare it to the other experiences reported in the literature. Such components, as previously stated, are: 1 Prenatal; 2 Labor and Birth; 3 Puerperium and Child Health; and 4 Logistical System.

All the participants agreed freely to participate and signed the Consent. This research was approved by the Center of Health Science's (Centro de Ciências da Saúde) ethics in research's committee, at the Federal University of Paraíba CAAE 42538515.4.0000.5188.

\section{Results and Discussion}

The analysis of care in the Stork Network in João Pessoa proved to be a challenge due to the complexity of the structuring of the services, the actions and the diversity in experiences that the perinatal care provides and because of the different subjects involved in its construction. In the sections below are the results found in the study regarding the implantation of this network in the referred city, as well as its repercussions on a local level, which may also be seen in Table 1.

\section{Prenatal}

The low-risk pregnant women are followed by primary care units. Even though João Pessoa has a 
Table 1. Main results of the implantation of the Stork Network Program in the city of João Pessoa, Paraíba, according to its components (Brazil, 2011)..

\begin{tabular}{|c|c|c|}
\hline Components & Actions Planned & Actions Planned \\
\hline Prenatal & $\begin{array}{l}\text {-Prenatal in the Basic Health Units (BHU) with early } \\
\text { reception; } \\
\text {-Reception with Risk and Vulnerability Classification; } \\
\text {-Access to high-risk prenatal; } \\
\text {-Access to tests; } \\
\text {-Vinculation to the delivery places; } \\
\text {-Information qualification; } \\
\text {-Sexual and Reproductive Health; } \\
\text {-STD/AIDS prevention and treatment; } \\
\text {-Support to pregnant women transport to the prenatal } \\
\text { and delivery place; }\end{array}$ & $\begin{array}{l}\text {-Established the municipal vinculation to the } \\
\text { low-risk and high-risk birth places as well as } \\
\text { the high-risk prenatal; } \\
\text {-In progress: implantation of visits for the } \\
\text { pregnant woman to the delivery place; } \\
\text {-Implantation of the Sexual and Reproductive } \\
\text { Health protocol (2014) in the Family Health } \\
\text { Units; }\end{array}$ \\
\hline $\begin{array}{l}\text { Labor } \\
\text { and Birth }\end{array}$ & $\begin{array}{l}\text {-Sufficiency of obstetric and neonatal beds; } \\
\text {-Adequacy of ambiance in the maternities; } \\
\text {-Good labor and birth practices based on evidence; } \\
\text {-Guarantee of a companion; } \\
\text {-Reception with risk classification (RRC); } \\
\text {-Encouraging implementation of horizontal teams; } \\
\text {-Encouraging implementation of management boards in } \\
\text { maternity wards and other co-management devices; }\end{array}$ & $\begin{array}{l}\text {-Completed reconstruction for the RRC } \\
\text { physical structure adequacy in one of the } \\
\text { maternities of the city; } \\
\text {-Four classes of the Volunteer Doulas Program } \\
\text { of the ICV; About } 35 \text { doulas have completed } \\
\text { their training through the program; } \\
\text {-Management board of the Stork Network } \\
\text { implemented in one of the maternities and } \\
\text { under implementation in another; } \\
\text {-Companion of choice in the ICV for the } \\
\text { antepartum, normal birth and postpartum. } \\
\text { Still difficult to insert the companion in the } \\
\text { surgical ward; } \\
\text {-Normal birth centers and houses for } \\
\text { pregnant women, newborns and mothers } \\
\text { vinculated to one of the maternities, waiting } \\
\text { for bidding; }\end{array}$ \\
\hline $\begin{array}{l}\text { Puerperium } \\
\text { and } \\
\text { Children Care }\end{array}$ & $\begin{array}{l}\text {-Promotion of breastfeeding and healthy complementary } \\
\text { feeding; } \\
\text {-Home visit in the 1st week after birth; } \\
\text {-Active search for vulnerable children; } \\
\text {-Sexual and reproductive health; } \\
\text {-STD/AIDS prevention and treatment; } \\
\text {-Orientation and offering of contraceptive methods; }\end{array}$ & $\begin{array}{l}\text {-Management board implemented in one of } \\
\text { the maternities and under implementation in } \\
\text { another. Municipal conductor group of the } \\
\text { Stork Network active; } \\
\text {-Partial guarantee of companion of choice } \\
\text { in the ICV. Companion of choice for the } \\
\text { antepartum, normal birth and post childbirth. } \\
\text { Still difficult to insert the companion in the } \\
\text { surgical ward; } \\
\text {-Normal birth centers and houses for } \\
\text { pregnant women, babies and mothers } \\
\text { vinculated to one of the maternities, waiting } \\
\text { for bidding; }\end{array}$ \\
\hline Logistic System & $\begin{array}{l}\text {-Access to safe transportation for pregnant women, } \\
\text { mothers and newborns; } \\
\text {-"always vacant" and plan of vinculating the pregnant } \\
\text { woman to the delivery place; } \\
\text {-Obstetric and neonatal beds regulation; }\end{array}$ & $\begin{array}{l}\text {-No SAMU for pregnant women, mothers and } \\
\text { newborns; } \\
\text {-No obstetric beds regulation; } \\
\text {-Overcharge of obstetric care in the city of } \\
\text { João Pessoa, especially concerning high-risk } \\
\text { childbirth and prenatal; }\end{array}$ \\
\hline
\end{tabular}


good coverage in primary care, this city has had, over the recent years, deficiency in the medical staff in some units, even with the presence of professionals from federal government program for provisioning of doctors. There are complaints, from doctors of the primary health care, about delay of the necessary exams for low risk pregnancies. So there was identified irregularity in supply of medications.

One of the issues that have advanced after the Stork Network Program was the municipal of the primary care units and the high-risk prenatal services to the reference maternities for childbirth. Despite the references being already established, some flexibility still remained for pregnant women to choose where they would be assisted, especially if they already had a previous positive experience with the service. Although the visit and information about the reference maternity had already been regulated by law in 2007, [12] the organization of the references was only made recently and there still is an incipient disclosure of that to the pregnant women during prenatal. Despite the existence of a reference between the primary care units of João Pessoa and the maternities, it is still uncommon for the low risk pregnant women to be able to visit their delivery place during prenatal. In a recent research about prenatal care in priority cities for reduction of child mortality rates in Legal Amazon and Northeast of Brazil, was identified that only $44.2 \%$ of women received instructions about delivery places during prenatal. [13]

\section{Labor and Birth}

There is still no birthing center in João Pessoa, even though projects have been approved by the federal government, but no constructions had started in the city. The birthing centers a with nurse midwifes are a good strategy of the study program to changing the obstetrical care model, considering they would be the place for low risk childbirth and, therefore, there would be a smaller chance of interventions. Another initiative to potentialize changes in the childbirth care model would be to incorporate obstetric nurses midwifes in the obstetric centers of traditional delivery centers for low risk childbirth, creating a collaborative environment and stimulating interdisciplinary work and reduction of unnecessary interventions. Both options seem to be met with resistance by part of medical professionals. The initiatives to stimulate good obstetric practices have been, so far, the creation of courses and workshops for the maternity teams and volunteer doulas program in one maternity.

Even before the Stork Network, professionals of the maternities of Paraíba linked to the Maternities Qualification Plan (PQM) performed, as one of the initiatives to change the obstetrical model, technical visits to excellence humanized delivery centers. A deployment of these visits, as foreseen in the PQM, was an activity of the team came in loco to promote humanized birth, in a sense of following the professionals and managers in the local reality, which happened in the PQM involved maternities of Paraíba. [14]

A Brazilian study discuss the collaborative model, in which there is integration between the doctor and the obstetric nurse and, possibly, including other professionals and doulas. The authors propose this model as an alternative to the hegemonic model, from a comparison of maternities in a Brazilian capital, which found a reduction of interventions such as episiotomies, artificial rupture of membranes and an increase in the use of non-pharmacological methods to alleviate pain. [15] A cross-sectional study with low-risk women attended in São Paulo, from 2003 to 2006, concluded that the assistance provided in the birthing centers was performed with fewer interventions and with similar maternal and neonatal results to the hospital results. [16]

One of the maternities of the study city has been going through changes with the implementation of the new reception protocol with a risk classification [17], to hear the women and sort their attendance. A reform was also made to improve the ambience 
of the place where is made the first consultation. The right to a companion of choice is still an issue in the SUS maternities of João Pessoa. One of the maternities managed to include, in the last few years, a male companion for normal birth, but the others are still restricted to female companions. The presence of the companion in the labor rooms is a recent change and is yet very restricted in surgical centers.

Despite the traditional obstetric model being undeniably hegemonic, there has been a surge of successful experiences in some maternities, with welcoming professional teams that promote good childbirth practices, which have been wielding fine results. Many obstetricians, pediatricians, nurses and technicians have been slowly changing the approach to labor and birth, enabling a respectful care to women and their decisions. These experiences have been gradually growing and gaining room among different professional categories. A very important experience in ICV was the volunteer doulas program, which is currently in 2016 in fourth class. In this program, the doulas act as volunteers in the maternity after completing training. The insertion of the doula, during labor and childbirth, is still a process which deploys some discomforts among members of the team, especially the medical team, but it has been bringing significant changes to childbirth care in the maternity, such as great satisfaction of the women who are accompanied by doulas.

\section{Puerperium and Comprehensive Care to Child Health}

Skin-to-skin contact between mother and baby, in the first moments of life, continues to be a challenge for the hospitals in João Pessoa. Right after birth, the local culture that the baby must remain in observation still prevails over contact with the mother. The child is placed beside his mother after birth, but breastfeeding is usually not possible in the first hour of life, as well as the late clamping of the umbilical cord. Rooming mother and baby together is not done from birth on, since the practice to take the baby to the admission room still persists, keeping him away from the mother for a few hours.

The milk banks carries out a breastfeeding promoting work at universities, school, industries, etc. Its perform the training of workers of their reference maternities, as well as campaigns to collect glass jars for breast milk donation at the community. Another action of great impact in child care, since prenatal, was the creation of the Pediatric Cardiology Network of Pernambuco-Paraíba (RCP). The RCP was an initiative of the integration between professionals who assisted children with congenital heart disease in the state. From this articulation, it was established a service where screening of children with heart disease is done through direct integration between 21 maternities that communicate through online conference, which are, together, responsible for $90 \%$ of the births in the state's public network. This screening is done though pulse oximetry and the children are accompanied by the pediatric cardiology clinics. Besides, permanent training and education are given to teams who are a part of this network. It is a way to articulate a network of care through their own information and communication technologies and using social networks as a way of communication between doctors of the state, developing actions that range from clinical care to the indication and monitoring of patients with surgery needs, qualifying, at the same time, access and care to children who have cardiovascular problems. From three years of networking, this group organized a bigger assistance front which integrates the Perinatology Network of the State. In this network, the main objective is to capacitate the professionals who work in services with no Intensive Neonatal Care Units, in order to offer an adequate guided assistance. For that purpose, professionals with appropriate technical qualification perform orientation through online shifts, until the child has access to a unit that can meet his needs with a high complexity structure. Thus, the perinatology group acts 
by avoiding early interruption of pregnancy, with appropriate assistance to the mother and neonate in the labor room, even in places where there is no structure to provide this service, therefore guaranteeing precise information until the transference to a more adequate place and safe, quality transport for the mother and baby. Whenever possible, intra-uterus transportation to an adequate place is prioritized.

\section{Logistical System: Sanitary Transport and Regulation}

The Logistical System related actions of the Stork Network have little developed in João Pessoa. The Mobile Emergency Care Service does not have a specific outline for pregnant women and baby transport, despite the attempt of adequacy, with capacitation of the local neonatal reanimation and transportation of newborn under risk team, and the attempt of habilitation. The absence of obstetric state regulation is the main difficulty to the logistical system operation, which causes women in obstetric emergency and threat of premature labor situations to go from one hospital to another looking for a room.

The ICV has a very positive culture of providing care to all the patients who come looking for the service, according to the idea of having always vacancy. However, the fact that there is no regulation for obstetric beds in the state leads to the overcharge of care in the two largest cities of the state.

\section{Conclusions}

The network of care for women in pregnancy, labor and puerperium and for children up to two years old has been slowly going through changes in the last few years, partly influenced by the changes in public policies in this area, coordinated by the Ministry of Health, and mainly by qualification, though slow, of the health system on state and municipal levels. Since 1994 there has been an expansion of the number of family health care units in João Pessoa and the qualification of the physical structure of some of them, which is essential to any service network's organization. Regarding perinatal care, the primary care is essential to the monitoring of the pregnant woman, the woman and the newborn under low-risk.

We realize that, in general, there is still an incipient implantation of central aspects of the Stork Network Program in João Pessoa. The fact that the existent projects for birthing centers are still in paper is a symptom that the municipal and state management prioritizes a care model centered in the hospital. Many of the changes in the care model come from the articulation between subjects/actors committed to childbirth humanization. Currently, the neonatal mortality rates are found to be slightly reduced in many regions of Paraíba, including the capital, but there is also a simultaneous growth in maternal mortality rates: the number of maternal deaths in 2015 already equates to the number of these deaths in all of 2014. Establishing a facility for births for low risk women, with higher insertion of obstetric nurses midwifes, and obstetric centers only for high-risk childbirth, would probably represent a significant change in care.

Obstetric violence is still undeniable in Brazil. In general, obstetric violence is understood as various forms of aggression suffered by women, may it be physical or psychological, including episiotomies or unnecessary caesarians, disdain or irony during communication with the patient and not taking her decisions into consideration during the care. Its interesting the quaternary prevention and obstetric violence, stating that the overcoming of the second depends on a change in the biomedical model for prenatal and childbirth; to this end, the quaternary prevention would be the base for participatory development of childbirth plans and social participation in the fight for childbirth humanization. The quaternary prevention, however a highly debated concept in primary care environment, has a signifi- 
cant approach to good obstetric practices, due to having, in its core, the parsimony to not unnecessarily intervene, recognizing that interventions and procedures can also lead to harm, and going back to one of medicine's essential principles: primun non nocere. [18]

The creation of management boards in the maternities and of the state and municipal conductor groups is an important step towards shared management of the policy, which is expected, doubtlessly, to reflect on the relations between managers and professionals and between professionals and patients.

\section{Competing and Conflicting Interests}

All the authors have no conflict of interest

\section{References}

1. Ministério da Saúde. Gabinete do Ministro. Portaria n 1.459, de 24 de Junho de 2011. Institui, no âmbito do SUS a Rede Cegonha. Brasília: Ministério da Saúde. 2011.

2. Cavalcanti PCS, Gurgel Júnior GD, Vaconcelos ALR, Guerrero AVP. Um Modelo Lógico da Rede Cegonha. Physis Revista de Saúde Coletiva. 2013; 23(4):1297-1316.

3. Carneiro RG. Dilemas antropológicos de uma agenda de saúde pública: Programa Rede Cegonha, pessoalidade e pluralidade. Interface - Comunicação, Saúde, Educação. 2013; 17:49-59.

4. WHO. Care in normal birth: a practical guide. In: Technical Working Group WHO, 1996.

5. Ministério da Saúde. Gabinete do Ministro. Portaria n 569 de 1 de junho de 2000. Brasília: Ministério da Saúde, 2000.

6. Rocha JA, Novaes PB. Uma reflexão após 23 anos das recomendações da Organização Mundial da Saúde para parto normal. Femina. 2010; 38(3).

7. Delgado Nunes V, Gholitabar M, Sims JM, Bewley S. Intrapartum care of healthy women and their babies: summary of updated NICE guidance. Vol 349; 2014.

8. Shah N. A. NICE Delivery - The Cross-Atlantic Divide over Treatment Intensity in Childbirth. New England Journal of Medicine. 2015; 372(23):2181-2183.

9. Chaillet N, Dumont A, Abrahamowicz M, et al. A ClusterRandomized Trial to Reduce Cesarean Delivery Rates in Quebec. New England Journal of Medicine. 2015; 372(18):1710-1721.

10. Ministério da Saúde. Sala de Situação de Saúde. Datasus. Ministério da Saúde, 2015.
11. Abrahão AL, Merhy EE, Gomes $M P C$, et al. O pesquisador IN-MUNDO e o processo de produção de outras formas de investigação em saúde. In: Gomes MPC, Merhy EE, eds. Pesquisador IN-MUNDOL um estudo da produção do acesso e barreira em saúde mental. Porto Alegre: Rede UNIDA; 2014.

12. Brasil. Lei 11.634, de 27 de Dezembro de 2007; 2007.

13. Leal MC, Theme-Filha MM, Moura EC, Cecatti JG, Santos LMP. Atenção ao pré-natal e parto em mulheres usuárias do sistema público de saúde residentes na Amazônia Legal e no Nordeste, Brasil 2010. Revista Brasileira de Saúde Materno Infantil. 2015; 15:91-104.

14. Dittz ES, Caldeira KA, Madeira LM. Plano de Qualificação das Maternidades: A Participação do Hospital Sofia Feldman. In: Ministério da Saúde. Cadernos HumanizaSUS: humanização do parto e do nascimento. Vol IV. Brasília: Ministério da Saúde; 2014.

15. Vogt SE, Silva KS, Dias MAB. Comparação de modelos de assistência ao parto em hospitais públicos. Revista de Saúde Pública. 2014; 48:304-313.

16. Schneck CA, Riesco MLG, Bonadio IC, Diniz CSG, Oliveira SMJV. Resultados maternos e neonatais em centro de parto normal peri-hospitalar e hospital. Revista de Saúde Pública. 2012; 46:77-86

17. Ministério da Saúde. Manual de acolhimento e classificação de risco em obstetrícia. Brasília: Ministério da Saúde, 2014.

18. Tesser CD, Knobel R, Andrezzo HFA, Diniz SG. Violência obstétrica e prevenção quaternária: o que é e o que fazer. 2015; 10(35):12.

\section{Publish in International Archives of Medicine}

International Archives of Medicine is an open access journal publishing articles encompassing all aspects of medical science and clinical practice. IAM is considered a megajournal with independent sections on all areas of medicine. IAM is a really international journal with authors and board members from all around the world. The journal is widely indexed and classified Q2 in category Medicine. 